habits, localities, etc., so that by the end of the quarter almost every member of the class had acquired a fair introduction to the science and had an intelligent appreciation of its importance as related to agriculture.

\title{
LIFE HISTORY OF THE RICE WEEVIL (CALANDRA ORYZA L.) IN ALABAMA
}

By W. E. Hinds and W. F. Turner

An examination of the literature relating to this species shows that our really definite information as to its life history is very scanty indeed. Only scattered and incidental references to isolated facts have been recorded in spite of its great economic importance. One reason for this is, doubtless, that the injury done by this insect is greatest in those sections of the country where economic entomology is but a comparatively new study. Another reason may be that its work has been confused with that of its close relative $C$. granaria.

In the United States, certainly, Calandra oryza is the far more important species of the two and here its injury seems to be of greatest importance in the Gulf and South Atlantic States especially. This is primarily on account of the milder winters and the longer season of activity during the fall when they may multiply most rapidly. The injury done by this species would seem to be one of the factors which has restricted the raising of corn and the production of livestock and tended to promote the "one-crop" system of cotton culture which has generally prevailed for a generation past. With the advance of the Mexican cotton boll weevil (Anthonomus grandis Boh.) the rice weevil becomes of increasing importance since the plan of fighting the boll weevil involves, as a rule, the production of more corn and the storage of the crop until it can be fed out to livestock. The rapid depreciation of stored corn has retarded the general adoption of this practice.

In this paper we can attempt to give only a general statement of the results of observations which have been accumulating in this office during the past two or three years. But we believe that much of the data will be welcomed by other workers, especially by those in the South. We cannot attempt to record any results of experiments looking to the control of the pest, but shall record the facts of life history in more detail than would appeal to the average farmer for whom a bulletin may later be issued.

The stages of the insect may be first considered:

The Egg.-The egg of the rice weevil is always deposited within the kernel of some grain. It is regularly elliptical or sometimes rather 
"pear-shaped," with the larger end outward as it rests in the grain (Pl. 7 , fig. 2). The covering membranes are thin and of an opaque white color. The average length of eggs is about $0.665 \mathrm{~mm}$. by about $0.295 \mathrm{~mm}$. thickness at the larger part. The young larva can be seen through the egg covering shortly before it is ready to hatch. Hatching occurs in an average of three days from deposition of the egg with a mean temperature of between $60^{\circ}$ and $65^{\circ} \mathrm{F}$. There appears to be a considerable mortality during the egg stage as not nearly as many larvæ develop in corn as there are eggs deposited, but the exact proportions have not been determined. It appears to be fully 50 per cent, however.

The Larva.- This stage has been figured by a few writers. Photographs are here shown of the young larva as it hatches from the egg and also of the fully grown larva (Pl. 7, figs. 3,5 ). The grub is of a creamy white color except the head which is brownish shading to nearly black at the tips of the mouth-parts. It is very thick bodied, with the ventral line approximately straight while the dorsum is almost semi-circular. There are three larval stages as shown distinctly by the measurements of heads. In the first stage the head averages approximately $0.22 \mathrm{~mm}$. in breadth at its widest part; in the second stage, $0.33 \mathrm{~mm}$. and in the third stage $0.64 \mathrm{~mm}$. The first larval stage requires about three days, the second four days and the third nine days on the average, with mean temperatures of between $60^{\circ}$ and $65^{\circ} \mathrm{F}$. There is then a distinct prepupal stage in which the forming pupa is plainly visible through the unshed larval skin lasting for usually one day. The entire larval stage, therefore, requires between sixteen and seventeen days on the average, with a common range of between fifteen and nineteen days under usual temperature conditions. The pupal cell is always formed within the kernel and may be either in the heart of the kernel or near its exterior.

The Pupa.-This instar is somewhat longer and more slender than was the grub before it (Pl. 7, fig. 6). There seems to be considerable variation in length of this stage at the same period, with the average at about six days and the range between three and nine days. Considerable brown coloration appears before the pupal skin is shed. After the insect has become adult it still remains within the kernel for several days to harden and fully mature before it makes any attempt to escape.

Naturally, with all of the immature instars, the duration of the stage is very largely determined by prevailing temperature conditions. The records that have been given relate to observations ranging from about the middle of August to the early part of November in the latitude of Auburn, Ala. The breeding of weevils continues more or less 
steadily throughout the winter provided the temperature remains sufficiently high. The occurrence of a particularly cold snap, as when temperature falls to below $10^{\circ}$ above zero, while it does not exterminate the weevils, still appears to destroy a large part of the immature stages and many adults and thus greatly retards subsequent multiplication and injury by the pest later in the winter. As a rule the greatest damage by these weevils is done before the end of December, in this State, and thereafter to corn that is stored beyond the following April.

During the winter season, as from December 15 to March 15 the larval stage has been known to be extended to beyond 115 days, or about four months, in spite of the fact that the infested corn was kept in a heated building where the day temperature averaged nearly $60^{\circ}$ with the night temperature probably $10^{\circ}$ to $15^{\circ}$ lower.

The Adult.-As has been said, the adult remains in the pupal cell for several days, usually three to four, for hardening and maturing before it starts to cut its way out of the kernel. Much feeding may then be done within the kernel without any attempt at emergence, so that we cannot reckon the life-cycle from observations based solely upon the time between oviposition and the emergence of the adult. Many weevils perish in their effort to escape from the kernel, being found wedged in the exit hole, usually with only the head, prothorax and forelegs free.

At an average temperature of about $63^{\circ}$, development from oviposition to the emergence of the adult may take place in about thirty-two days. The general average, however, is rather longer than this and for the first field generation, appears to be about six weeks and for the second field generation between seven and eight weeks. This is between about the first week of August and the last of October.

The adult rice weevil, or "black weevil," as it is often called in the South, is a rather slender, cylindrical beetle, averaging in length of body from the front margin of the prothorax to the tip of the body, about $3.5 \mathrm{~mm}$. and for the length of head and snout about 1.6 $\mathrm{mm}$. The normal color is a very dark brown or nearly black and is uniform except for four reddish spots located one at each corner of the wing-covers. The prothorax is densely and uniformly punctured as are the elytra (Pl. 7, fig. 1). The reddish spots and the punctation serve to distinguish this species from $C$. granaria. The average weight per weevil is approximately 0.003 gram, or more than 150,000 weevils per pound.

Distinguishing the Sexes.-This is not a difficult matter, although size and color do not appear to indicate it at all. In size, measurements of 20 females shows a body length averaging $3.5 \mathrm{~mm}$. and a head and snout length averaging $1.66 \mathrm{~mm}$. Among 20 males, the body length 


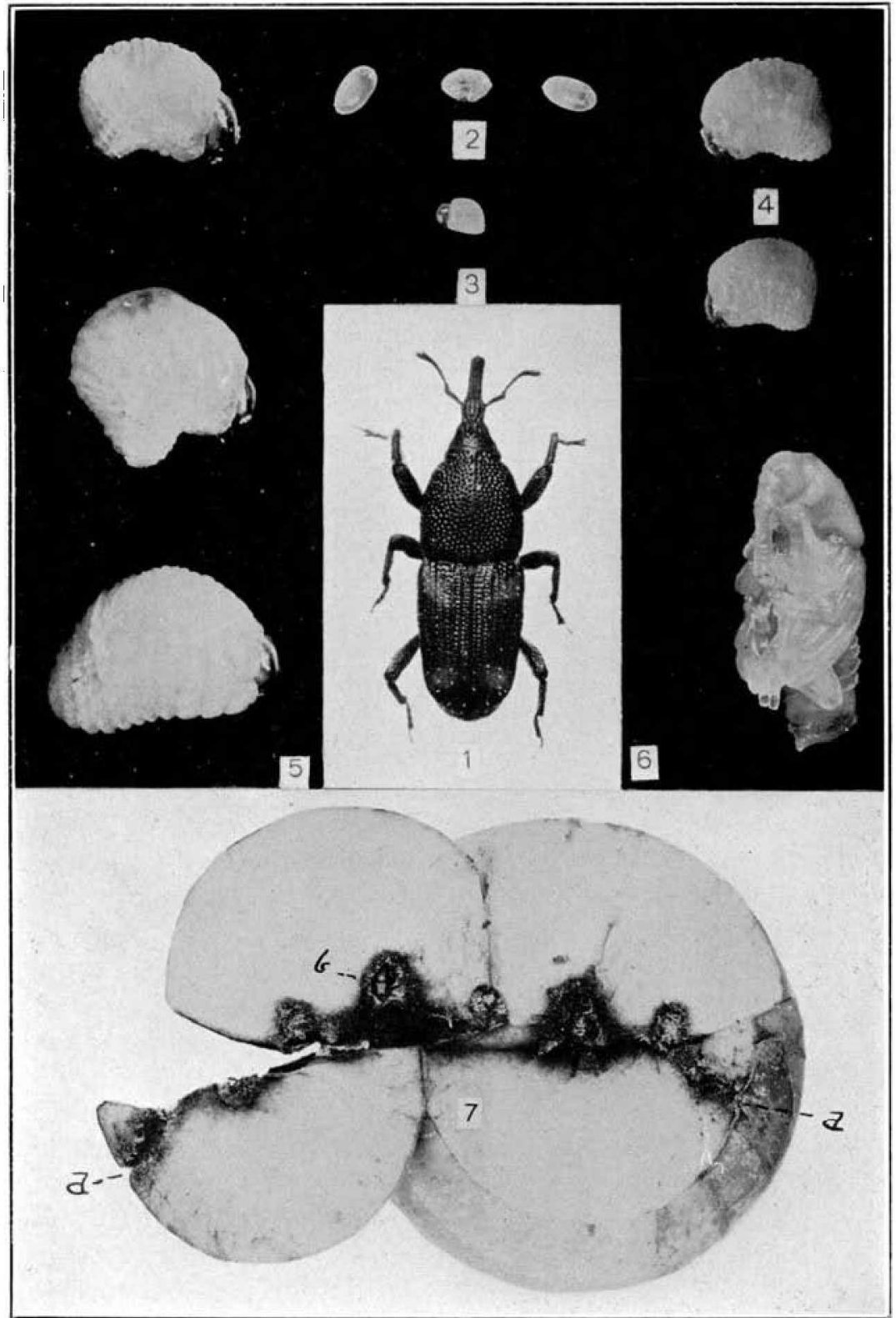

Rice wecvil stages (Calandra oryza Linn.) Fig. 1, adult male; fig. 2, three eggs fig. 3, first stage larva, just hatched; fig. 4 , two sizes of second stage larva; fig. 5, three sizes of third stage larva, the lower one full grown; fig. 6, pupa at middle stage; fig. 7 , adult, feeding effect on apple, $a$, point of entrance, $b$, adult at work. Figs. 1 to 6 enlarged $x 10$; fig. 7 natural size. (Original.) 
was $3.5 \mathrm{~mm}$. and head and snout $1.55 \mathrm{~mm}$. This shows that females average no larger in body, but have distinctly longer snouts than do males. Under the microscope or a good hand lens, there is little difficulty in separating the sexes solely upon the appearance of the snout. The male snout is plainly thicker and more deeply punctate than is that of the female.

The two sexes are produced in approximately equal numbers. On stored corn, however, many more males than females are likely to be found outside of the kernels while a larger proportion of the females are engaged in feeding on the inside of those kernels which show weevil emergence holes.

Spring Activity.-It is certain that many weevils hibernate in the fields. Large numbers were found in the course of the boll weevil investigations hibernating both in empty cotton bolls and more frequently in old corn stalks. They have been found moving in the field as carly as February in Texas after a very mild winter, and as early as January 30 in Alabama. Of course large numbers occur around corn cribs. It is evident, however, that in the field the rice weevil must have some other food than corn grain to survive the long season during which this is developing. What is this food normally? Of this we are not yet certain as observations are only scattering. Weevil adults are to be found in many locations before corn is ready for their attack, but their occurrence may not indicate that they are feeding there. We have no record of breeding occurring except on some grain and during the fall of the year in the open ficld.

Dissemination.-The possession of functional wings is another character in which this species differs from the "granary weevil" and it is very certain that it spreads in the field entirely by flight. They do not even crawl up the corn stalk to reach the ear but fly directly thereto. We do not know how far they may spread from field to field but it is certain that corn raised for the first time on ground at least a mile from where corn was grown the preceding. season is certain to become infested before it is ready to harvest. Our observations indicate that the season of greatest activity in flight is coincident with the maturing season for corn. Early corn serves to concentrate most of the weevils in the neighborhood and by presenting conditions favorable for the breeding of the weevils through so much longer time, it is ordinarily much more seriously injured by the weevils than is late maturing corn.

First Attack on Corn.-Rice weevils do not seem to be able to feed on any part of the corn plant except the grain. Weevils placed on young growing corn starved to death with no evidence of feeding. Weevils placed on corn in the milk stage fed somewhat and life was prolonged 
to about twice the starvation period at that season but there was no evidence of breeding on this corn. All observations show that the attack on corn does not begin until it has reached the "dough" stage. At this time the husk is drying and shrinking, so that it is also easier for the weevils to gain access to the kernels. In the South the "cotton boll worm" or "roasting ear worm," Heliothis obsoleta Fabr., is so abundant that very few ears indeed escape some injury from their attack and it is very noticeable that weevil injury is greater on ears which have been badly injured by those worms. They leave the door wide open for the entrance of weevils later on. The length and tightness of the corn shuck is a very important factor affecting the severity of early weevil injury.

Duration of Life Without Food.--Observations ranging from early spring to late fall show that these weevils cannot live long without food. In April the average was about nine days and in May only five days for the starvation period, while in August the average was seven days.

Duration of Life With Food.-Our breeding work has all been done with corn, although the weevil is reported as attacking other grains also. It seems that the adults cannot feed upon isolated kernels of fully matured hard corn as in all cases they died in the usual starvation period with no signs of feeding when so.confined. Where feeding can take place normally, the length of life is exceedingly variable, extending in many cases, where the winter season intervenes, to six or eight months. Males live longer than do females as a rule.

It is interesting to note that the only positive observations as to these weevils feeding in the field before corn matures shows that they attack immature fruit of peach and apple, sucking the juice and gradually forming cavities within which they may be entirely concealed and even present a real burrowing habit (Pl. 7, fig. 7). On such fruits weevils have been kept alive for more than six weeks in spite of a decayed condition of the fruit.

Mating and Reproduction.-Rice weevils are both polygamous and polyandrous. Mating may occur with both sexes within twentyfour hours of their emergence from the grain. Some feeding may have occurred in the grain and also in making their exit holes. A period of about three days then ensues before females are ready to begin oviposition. Subsequent matings are common and in laboratory breeding experiments it is evident that mating frequently results in more frequent oviposition, especially after a large number of eggs has been deposited.

Oviposition.-This occurs normally on corn at a spot that may be called an "outer angle" of the kernel. Kernels at the tip are usually 
first infested and later those near the butt of the ear. The female eats out a cavity large enough for the egg, occupying usually about forty-five minutes in the operation when the corn is fairly hardened, then turns, locates the cavity with the tip of the abdomen and inserts the fleshy ovipositor. The deposition of the egg requires only about three minutes and the cavity is then sealed over as the ovipositor is withdrawn. The top of the egg is just below the surface of the grain. The female will then rest for a short period before starting another cavity. Conditions are most favorable for both the adult and the young when eggs are deposited in corn which has just passed the "dough" stage. In this condition the grain can be cut with the thumbnail and may be characterized as a "hard gum" stage. All corns, no matter how hard they may become later, must pass through this stage during which they are subject to attack if weevils have access to the kernels. Long, close-fitting shucks may serve to so retard weevil entrance that the grain may harden and become more resistant to subsequent injury.

Rate of Oviposition.-This is a point upon which we have had no previous data. It has been interesting to find out the factors affecting the rate of egg deposition. Most important of these is evidently the degree of hardness of the kernel. With corn in the "gum" stage, the maximum record obtained was twenty eggs in twenty-four hours. Daily records of fifteen or sixteen eggs were not uncommon, while the average through a period of several weeks, with a number of weevils, was about seven eggs per day. Weevils which were laying ten or twelve eggs per day on "gum corn" would be checked to two or three eggs per day on hard corn.

The period of oviposition is nearly as long as the life of the female, beginning within a few days of her emergence from the grain. Eggs may be deposited until within a few days of death. The maximum oviposition period yet found is $\mathbf{1 1 0}$ days, but this female is still active at this writing. During this period 417 eggs have been deposited. Still another weevil deposited 374 eggs in the laboratory in addition to what she may have deposited in the fields before she was captured. The maximum record, however, includes the entire deposit as the weevil was bred.

Life Cycle and Generations.-The average duration of the life cycle during August and September is between seven and eight weeks. Generations, therefore, become wholly mixed within a short time. It appears, though, that about three generations are developed on early maturing corn before the middle of December and two generations with medium late corn. Infested corn, which has been kept in receptacles in the laboratory has shown but two generations for the 
entire season and it is evident from the length of life occasionally found that a single generation might span the entire season.

Mortality.-This appears to be greatest during the coldest part of the winter season, when large numbers of the adults, as well as many of the immature stages, die. Accordingly, in March, after an average winter in this locality, but 14 per cent of either immature stages or adults were found alive.

In the field, dưring the fall, largest mortality appears to be with eggs and young larvæ. There is also considerable mortality during the prepupal stage and with adults in the act of emergence.

Parasites are not uncommon and two or three species have been bred from immature stages of the weevil.

Parthenogenesis:- It is interesting to note that we have found strong evidence of the common occurrence of parthenogenesis among rice weevils. Unfertilized females deposit eggs occasionally but much more rarely than is normal. Many observations have shown that these eggs may hatch. We have bred a male and a female weevil from eggs deposited by a positively unfertilized female. Their development required about five months, from October to March, in a heated room.

\section{INJURIOUS INSECTS OF I9IO AT TREESBANK, MANITOBA}

By Norman Cridde

The areas covered by this paper contains most of the types of soil found within the Province of Manitoba and a fair percentage of the kind of crops grown. It also embraces open country and woodlands of different sorts, so that, on the whole, we might expect to find within its borders most of the insect pests that inhabit other portions.

Owing to an exceptionally dry season cereal crops were, gencrally speaking, very poor and this made the inroads of some insects, notably grasshoppers, much more difficult to control than they would otherwise have been; it also caused several pests of importance to be overlooked, the poor condition of grain being generally put down to unfavorable weather conditions.

\section{Insects Injurious to Grain and Grasses}

Hessian Fly, Mayetiola destructor. - Injury was reported to be rather extensive in some localities but investigation did not bear out the reports, but revealed that most of it was due to other insects.

The Greater Wheat-Stem Maggot, Meromyza americana.-This and probably the Lesser Wheat-Stem Maggot (Oscinis carbonaria) 